The woman may mean pain afterwards and this often arises from the back.

The clinical test is simple. After the pelvic examination the woman draws her knees up on to her chest and then the doctor gently presses the knees downwards even further In the classical case the woman can say immediately that that is the pain of which she complains. Sometimes she may notice the pain a few hours later. Further examination of the back should be made with the patient prone by pressing firmly along the lumbar spine and putting it passively into full extension by lifting her thighs off the couch and pressing again. With the patient on her side passive rotation of the lumbar spine can be tested in both directions. The object is to try to reproduce the pain whether it be vague abdominal pain and tenderness or dyspareunia. If the pain is brought on by one of these manoeuvres treatment can be directed to the back, often with highly satisfactory results.

The history of postural back pain is one of alternating periods of relief and exacerbation. Neither exercise nor rest fully relieve the pain. At the beginning of each of these there is some relief, but this does not last. The obvious example is going to bed, which brings relie (negated if there is sexual intercourse), but getting up in the morning is also a relief since the pain has returned even with prolonged rest. If gynaecologists and general practitioners would routinely ask about backache and do the appropriate simple tests in women with pelvic symptoms they could help a larger number of patients than they do. More importantly, overanxiety about pelvic symptoms may be prevented when their true cause in the back is demonstrated.

Philip Rhodes

Brockenhurst,

\title{
Children's coughs related to parental smoking
}

SIR,-Dr Anne Charlton emphasises the association between parental smoking and cough in children aged 8-19 years and assumes that passive smoking is the explanation (2 June, p 1647). An alternative mechanism may be the influence of smoking in pregnancy. Maternal smoking is known to predispose infants to respiratory illness but studies to date have not distinguished between the effect of passive smoking and that of smoking during pregnancy. ${ }^{1-3}$ Respiratory infections in infancy have an adverse effect on lung function in later childhood and the increased incidence of cough in Dr Charlton's subjects may be due to the effects of maternal smoking on the fetus. ${ }^{4} 5$ The finding of a greater influence of maternal than paternal smoking on respiratory symptoms supports this argument, whereas the finding of a higher incidence of cough in children with two parents smoking than in children with one parent smoking does not.

Probably both mechanisms are involved but their relative importance is yet to be shown. This should be borne in mind when making any inferences from Dr Charlton's paper. Evidence for the harmful effects of passive smoking is accumulating, but the mechanism whereby cigarettes cause respiratory symptoms in non-smoking children and infants has not been fully established.

St James's University Hospital,
Leeds LS9 7TF

K D Foot

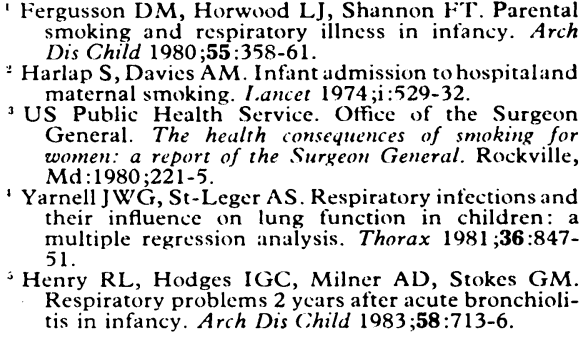

Medicines at school

SIR,-Some parents of children with chronic asthma or cystic fibrosis have pointed out to me that some school authorities confiscate medicines which the children, on doctors' instructions, have to take during school time. I have made inquiries at seven junior schools picked at random and can confirm the parents' stories. The heads (four out of seven) have acted without any reference to the child's doctor, the school clinical officer, or the parents. The reasons given were haphazardprotecting the normal children from Spinhalers, publicity about glue sniffing, Spinhaler over use, "a child on antibiotics should not be in the school in any case," and so on.

I have been reassured that all medicines were available in the heads' offices for the children to take on request. In practice such arrangements were unsatisfactory. One boy was "afraid to go and ask," a girl "forgot to ask," and another boy "could not find the head's office." In one case a direct request by a parent, a clinical officer, and a paediatrician that a child with moderate exercise induced asthma should be allowed to carry a Spinhaler was ignored.

A child with a chronic disease requiring regular treatment should have it unmolested even at school. It might be beneficial to set up a detailed inquiry into the prevalence of such practices in the United Kingdom so as to make general recommendations which would satisfy parents, their children, teachers, and doctors.

Peterborough Health Authority,
Peterborough PE3 6DA

J A Kuzemko

\section{Kielland's forceps delivery}

SIR,-I am pleased that Dr Conor Carr (2 June, p 1694) intends to carry out a retrospective survey on maternal morbidity after Kielland's forceps delivery but I would like to take issue with him on a few points. Firstly, he found my description emotive. I had tried to make it factual and to defuse this emotionally charged issue by making a case for the midforceps controversy to be subjected to clinical trial and scientific assessment.

Secondly, while epidural or spinal block is essential for good analgesia, I am not sure that its use would reduce neurological complications. It could be argued that abolishing pain might lead to even greater damage being in flicted. A recent report with some similarities to mine (failed rotation and occipitoposterior delivery with Kielland's forceps) showed postnatal paraparesis in spite of, or perhaps even because of, epidural analgesia. ${ }^{1}$

The main error in Kielland's forceps delivery with poor outcome is the human compulsion to complete a procedure once undertaken. While Kielland's forceps are still widely used and until poor risk prognostic factors are defined I can only ask obstetricians to consider the words of Professor John Huddleston "There will be times when even the most experienced obstetrician will anticipate an easy midforceps operation but encounter difficulty in application, rotation, or traction instead. Critical to our ability to retain midforceps as a reasonable and acceptable method of effecting vaginal delivery is that in such cases the forceps attempt should be promptly abandoned and abdominal delivery effected. There is simply no justification in such a setting for persistently attempting vaginal delivery."'2

SHEILA SHEERIN

Princes Risborough

Bucks HP17 9AS

Newman B. Postnatal paraparesis following epidural analgesia.

Huddleston JF. Is there a place in modern obstetrics for mid forceps rotations or deliveries? International Correspondence Society of Obstetricians and Gynaecologists $1983 ; 24$, no $23: 183$.

\section{Analgesia in acute pancreatitis}

SIR,-We agree with Mr S L Blamey and others (19 May, p 1494) that "potential addiction to narcotics in young adults presenting with recurrent episodes of pancreatitis, often secondary to alcohol abuse, is a cause for concern among clinicians treating this disease." We must take issue, however, with the comment that "buprenorphine appears to have little potential for physical dependence."

We have a patient with a history of addiction to alcohol and dipipanone for whom the latter drug was replaced with buprenorphine. The end result of a harrowing story is that he is now firmly addicted to buprenorphine and our attempts to wean him off it have so far been unsuccessful. Part of the problem is that buprenorphine is not a controlled drug and various bodies, including the Committee on Safety of Medicines, have been interested but powerless to take action. The manufacturers of buprenorphine (Temgesic) have indicated to us that they recognise the possibility of addiction, particularly in those who have a history of opiate abuse. Apparently there is some overlap of use of the pain receptors by both these drugs and cases of addiction have been documented. Our experience of this case has taught us to be very respectful of the possible risk of habituation to buprenorphine.

N M BROWN J W STRACHAN

The Health Centre,

Girvan,

\section{Acute scrotal pain}

SIR,-Dr Hilary King and Mr Peter Whelan emphasise the need for urgent exploration of the scrotum in young men who present with acute scrotal pain (26 May, p 1576). Intermittent scrotal pain, which may be due to repeated attacks of torsion of the testis, is infrequently documented but can result in testicular atrophy even without the testis undergoing acute torsion. ${ }^{1}$ We recently reported a series of 26 patients presenting over four years with torsion of the testis in which 12 had the intermittent variety. ${ }^{2}$ All symptoms in patients in the latter category cleared after fixation of the testes. Failure to recognise this condition may be because its presentation is not so 
dramatic as that of acute torsion. Castration in these cases results not from neglect, but from lack of identification of the problem.

\section{DAVId P SELLU}

J A LYNN

\author{
Ealing Hospital, \\ Middlesex UB1 $3 \mathrm{HW}$ \\ ' Futter NG, Mackay DE, Murphy PG. Recurrent \\ torsion of the testis in adults. Can Med Assoc \\ Sellu DP, Lynn JA. Intermittent torsion of the testis. \\ $7 R$ Coll Surg Edinb 1984;29:107-8.
}

SIR,-I agree with Dr Hilary King and $\mathrm{Mr}$ Peter. Whelan about the need for urgent surgical appraisal of patients with acute scrotal pain (26 May, p 1576). One must also be aware of the possibility of pain being referred to the scrotum from retroperitoneal pathology as highlighted by the following unusual case.

A 10 year old boy developed pain in the right testicle which awoke him from sleep. His general practitioner referred him directly to hospital with a tentative diagnosis of torsion of the testicle. It was noted, however, that the clinical picture was atypical in that the scrotum was not tender to palpation and the testicular anatomy was normal. On arrival the boy was still complaining only of continuous pain in the right testicle. On examination the findings had progressed since the initial consultation and he had marked circumoral pallor, a tachycardia pyrexia, and tenderness in the right iliac fossa. The genitalia were normal. An acutely inflamed retrocaecal appendix was removed and he made an uneventful recovery.

Presumably the inflammation was stimulating either the adjacent testicular sympathetic innvervation or the genitofemoral nerve resulting in the referred pain. No patent processus vaginalis was seen at laparotomy although these have been known to be affected by peritonitis and to cause similar discomfort

University College Hospital,
London WC1E 6AU

Joseph L Peters

\section{Assessment of gastric cancer' by laparoscopy}

SIR,-Mr E Gross and others show the value of laparoscopy in the management of these patients (26 May, p 1577). We are conducting a study of laparoscopy in oesophageal and gastric carcinoma and suspected intra-abdominal metastatic spread. In our first 50 patients $(23$ with oesophageal carcinoma, 14 with gastric carcinoma, and 13 with suspected metastatic spread) we avoided laparotomy in $58^{\circ}$. There was no mortality or morbidity associated with laparoscopy, and only one failure due to adhesions from previous surgery. The accuracy as determined by laparotomy, biopsy, or necropsy was $96^{\circ}{ }_{0}$. Laparoscopy showed nodal and peritoneal spread which could not have been diagnosed by scanning in 15 patients. There are the added advantages of biopsy under direct vision of secondary deposits and the alleviation of symptoms in inoperable patients by endoscopic intubation at the time of laparoscopy. Laparoscopy should be undertaken as a primary investigation in oesophagogastric carcinoma. This would avoid the morbidity and mortality of an exploratory laparotomy and further discomfort and emotional trauma to these patients with advanced disease and low cure rates. It would also allow better planning for curative surgery in selected patients.

Welsh National School of Medicine,

A Shandall

C JOHNSON

L R Cflestin

Frenchay Hospital, Bristol

Diabetic ketoacidosis and ruptured ectopic pregnancy: a fatal combination

SIR,-The real lesson from Dr M J Glynn's and Mr D Elliot's case history is that all acutely critically ill patients need invasive haemodynamic monitoring (28 April, p 1287) A falling central venous or pulmonary capillary wedge pressure would have signalled the need for an increase in intravascular volume, and such treatment might well have avoided a fatal outcome.

Thomas P CRIPPs

Guy's Hospital,
London SE1 9 R'T

\section{Manpower problems in general surgery}

SIR,-Mr N G Rothnie the chairman of the Specialist Advisory Committee in General Surgery has provided data on the number of time expired senior registrars in the specialty (9 June, $p$ 1764)

To understand the serious imbalance in general surgery these figures must be taken in conjunction with figures for projected consultant vacancies. In general surgery, with a negative growth of minus $0.3 \%$ in the number of consultants over the past five years, vacancies equate with projected retirements, 20-29 per year in the NHS and three or four university appointments per year.'

With 199 higher surgical trainees waiting for fewer than 34 posts per year it is surprising that only 23 are still waiting after six years. To call those who have only been in a post for four years "time expired" is inappropriate. Premature appointments for some mean inevitable delays for others.

P W WENHAM

Department of Surgery,

University Hospital,

1 DHSS Medical Manpower Division. Medical and Dental staffing prospects: the NHS in England and
Wales, 1983 . Health Trends $1984 ; 16: 25-9$.

\section{Cytomegalovirus infections in renal transplant recipients}

SrR,-The recent leading article on cytomegalovirus infections in renal transplant recipients by Dr T O Nunan and Professor J E Banatvala (19 May, p 1477) highlighted the problem of treatment in established disease. We have reporced elsewhere our preliminary uncontrolled experience with hyperimmune anticytomegalovirus immunoglobulin in renal transplant patients with severe cytomegalovirus infections. ${ }^{2}$ Two thirds of our patients showed prompt and sustained response within a day or two of this treatment, with lysis of fever, resolution of pneumonitis, a rise in white cell count, and improvement in renal function and liver function tests.
We have now set up a placebo controlled double blind trial of hyperimmune anticytomegalovirus immunoglobulin for severe cytomegalovirus infection, and we are willing to enrol patients from any British renal transplant unit. Clinicians who wish to collaborate should contact one of the clinical coordinators $(\mathrm{Dr}$ A J Nicholls, 0392 215581; Dr C B Brown, 0742 26484) if they have a renal transplant patient with severe cytomegalovirus infection whom they wish to enrol in the trial.

ANTHONY NichOLLS

Renal Unit,

Royal Devon and Exeter Hospital (Wonford)

Royal Devon and
Exeter EX2 5DW

C B BROWN

Department of Nephrology and Transplantation,

Royal Hallamshire Hospital, Sheffield $5102 \mathrm{JF}$

B CuTHBerTSON

Protein Fractionation Centre, Protein Fractionation Centre,
Edinburgh EH17 7QT

P L YAP

D B L MCClelland

Edinburgh and South East Scotland Blood

Transfusion Service,
Edinburgh EH3 $9 \mathrm{HB}$

' Nicholls AJ, Brown CB, Edward N, Cuthbertson B, Yap PL, McClelland DBL. Hyperimmune immunoglobulin for

Brown CB, Nicholls A I Edward N, Cuthbertson B Yap PL, McClelland DBL. Hyperimmune $B$, munoglobulin therapy for cytomegalovirus infections in renal transplant patients. Proc Fur Dial Transplant Assoc 1983;20:271-9.

\section{In vitro fertilisation}

SIR,-The announcement that two surrogate pregnancies are proceeding in England confirms my worst fears (expressed in BMA council and at the Annual Scientific Meeting at Cambridge) about the declaration by BMA council that it is unethical for surrogates to be used. I argued for licensing of doctors engaged in in vitro techniques because I felt that ethical constraints would prove cumbersome and unresponsive in this rapidly expanding field. Possibly no doctors were involved in inseminating the surrogates, but the sums of money quoted would be a considerable attraction to some doctors whose idea of medical ethics might not correspond with that of BMA council.

Ten years ago Mr Steptoe (who will only use techniques that have been approved by his hospital ethical committee) stated that in vitro fertilisation was possible and five years ago he demonstrated this to be correct. Sadly it has taken this long for the BMA's central ethical committee to respond, in what I regard as an inadequate fashion. It is essential for this committee to be forward looking and function efficiently if the standing of the association and the profession is not to suffer. I hope that representatives attending the annual representative meeting this summer will look critically at this particular area.

J M CunDy

Lewisham Hospital,

London SE13

${ }_{*}^{*}$ The secretary writes: The ethics of in vitro fertilisation and of surrogate motherhood have been under consideration by the central ethical committee since 1982. A working group was appointed and in 1983 gave evidence to the Warnock Committee, which is examining recent and potential developments in 